\title{
Post Covid Multisystem Inflammatory Syndrome with Cervical Lymphadenopathy In A Young Adult
}

\author{
Blessy Samu', Abhijith C1*, Sulfath TS ${ }^{2}$, Ashique EP² \\ 'Department of Pharmacy Practice, S.C.S College of Pharmacy, Harapanahalli, Karnataka, INDIA. \\ ${ }^{2}$ Clinical Pharmacist, IQRAA International Hospital and Research Centre, Calicut, Kerala, INDIA.
}

\begin{abstract}
Multisystem inflammatory syndrome-children is considered as a paediatric hyper inflammatory condition prompted by severe acute respiratory system coronavirus 2, which has multi-organ involvement. Among them cervical lymphadenopathy is an unusual presentation in multisystem inflammatory syndrome-children. A case study of 17 year old post coronavirus disease 2019 male patient, whose clinical presentation and elevated inflammatory markers on blood tests lead to the diagnosis of multisystem inflammatory syndrome-children is explained here. Evidence from computed tomography, ultrasonography and fine needle aspiration cytology revealed the rare presentation of multisystem inflammatory syndrome-children with cervical lymphadenopathy. Standard guidelines were followed in the treatment of the condition and the prognosis was closely monitored clinically, the
\end{abstract}

available objective evidences manifested progressive response and outcome.

Key words: Multisystem inflammatory syndrome-children, Cervical lymphadenopathy, Fine needle aspiration cytology, Severe acute respiratory system coronavirus 2, Kawasaki disease.

Correspondence

Dr. Abhijith C,

Department of Pharmacy Practice, S.C.S College of Pharmacy, Harapanahalli, Karnataka, INDIA.

Email id: abhijithanu664@gmail.com

DOI: 10.5530/jyp.2021.13.61

\section{INTRODUCTION}

Since the outbreak of COVID-19 in China, the widespread of the virus SARS-COV-2 caused 18.3 million infections around the globe till the $4^{\text {th }}$ Jan 2021 and still spreading widely with a mutation in the virus. ${ }^{1}$ The acute COVID-19 infection can trigger several post-infection complications, including myocarditis, fibrosis, kawasaki disease. ${ }^{2}$ As per the various reports, the COVID-19 among children is less severe than adults with mild upper respiratory symptoms. ${ }^{3,4}$ However, on May 14, 2020, the Centre for Disease Control and Prevention released a health advisory on severe life-threatening complications of paediatric COVID-19 termed MIS-C. ${ }^{5}$ The first case was initially reported from the United Kingdom, where eight children with SARS-COV-2 infection presenting as a hyperinflammatory syndrome with multiorgan involvement. ${ }^{6}$ The laboratory incidence confirms SARS-COV-2 infection among the 21-year-old category was 322 infections per 100000 and the MIS-C was 2 per $100000 .{ }^{2}$ CLA is one of the clinical features of MIS-C, that had only seen in $6 \%$ patients who were hospitalized for COVID-19. ${ }^{7}$ Henceforth we will describe the first case of MIS-C post-COVID-19 infection with CLA in India was reported in a young adult.

\section{CASE REPORT}

A 17-year-old male patient was presented to Medical intensive care unit with chief complaints of fever, right sided neck pain and odynophagia. Patient has cold and dust allergy. The general examination revealed that he was febrile $\left(100^{\circ} \mathrm{C}\right)$ and other parameters were normal.

USG of neck showed lymph node enlargement (Figure 1), CT detected CLA (Figure 2) and FNAC detected blood with small mature lymphocytes and collection of histiocytes (Figure 3). Immunoglobulin-M report showed positive. Laboratory examination exhibited platelets: 7800 cells/ cumm, C-reactive protein: $241 \mathrm{mg} / \mathrm{L}, \mathrm{D}$-dimer: $6501.71 \mathrm{ng} / \mathrm{ml}$ and serum ferritin: $2474 \mathrm{ng} / \mathrm{ml}$. From the above clinical investigations, the final diagnosis done was Post COVID-19 MIS-C with CLA.

Patient was treated with paracetamol, cefoperazone-sulbactum and intravenous immunoglobulin. He was given with 3 days of antibiotics (doxycycline and amoxicillin clavulanate) followed by 7 days of high dose corticosteroids (injection methylprednisolone). The patient was discharged with the below medications (Table 1) after his condition showed improvement. He was advised for follow up.

\section{DISCUSSION}

MIS-C is a newly recognized spectrum of diseases associated with SARSCOV-2, which mimic KD and toxic shock syndrome. ${ }^{8} \mathrm{MIS}-\mathrm{C}$, deliberates in the occurrence of secondary to a cytokine storm, which has the ability to damage numerous organ system. The recent outbreak of this disease has promoted the health counselors to propose several definitions and names. ${ }^{9}$ These definitions were based on the presence of prolonged fever, multi-organ dysfunction, laboratory evidence of hyperinflammation, with or without SARS-COV-2 infection or exposure, and no alternative cause to explain the clinical presentation.

Considering the finding done children could still develop MIS-C despite being asymptomatic of COVID-19 disease. ${ }^{10,11}$ Reports reveal that MIS-C appears within 3-4 weeks after SARS-COV-2 infection. ${ }^{2}$ This may elaborate why the antibodies show positive to SARS-COV-2, but negative to MIS-C evaluation. ${ }^{12,13}$ MIS-C- Kawasaki like syndrome shares several common factors with KD that are independent of SARS-COV-2 infection and that has been reported in an adult with rapid remission of clinical and laboratory features following the use of methylprednisolone pulse therapy, IVIG and aspirin with tapering Prednisolone., ${ }^{8,14}$ Subsequently, another case of MIS post COVID-19 in an adult has been reported which meets the American heart association criteria for KD 


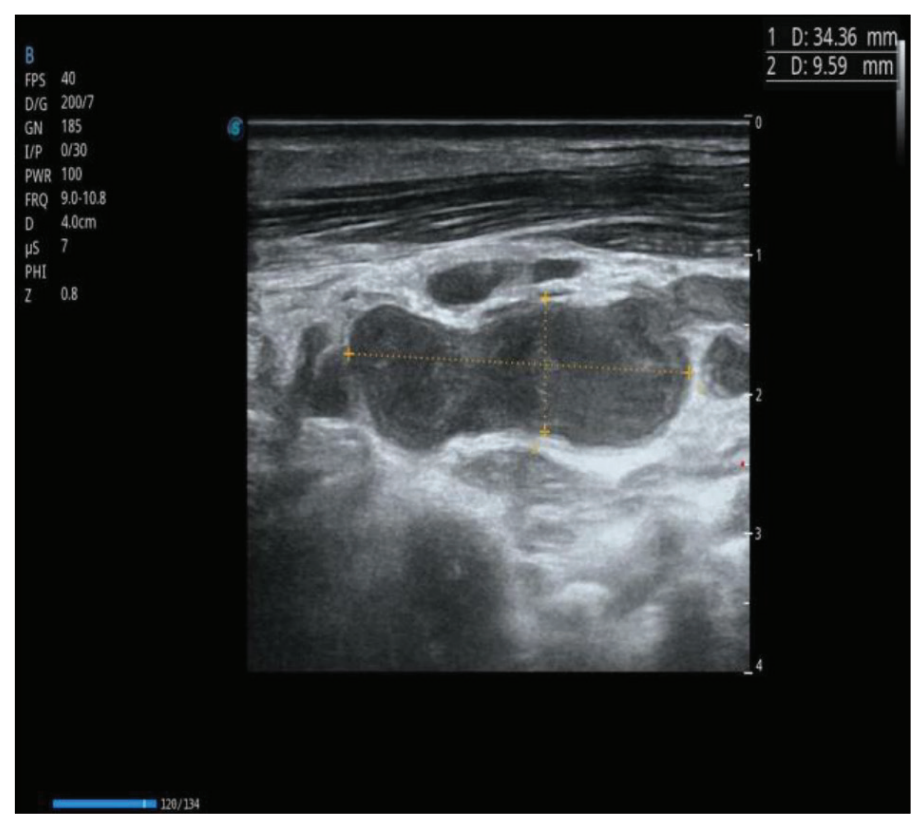

Figure 1: USG showing multiple enlarged lymph nodes in the level II, III and $\checkmark$ regions on right side.

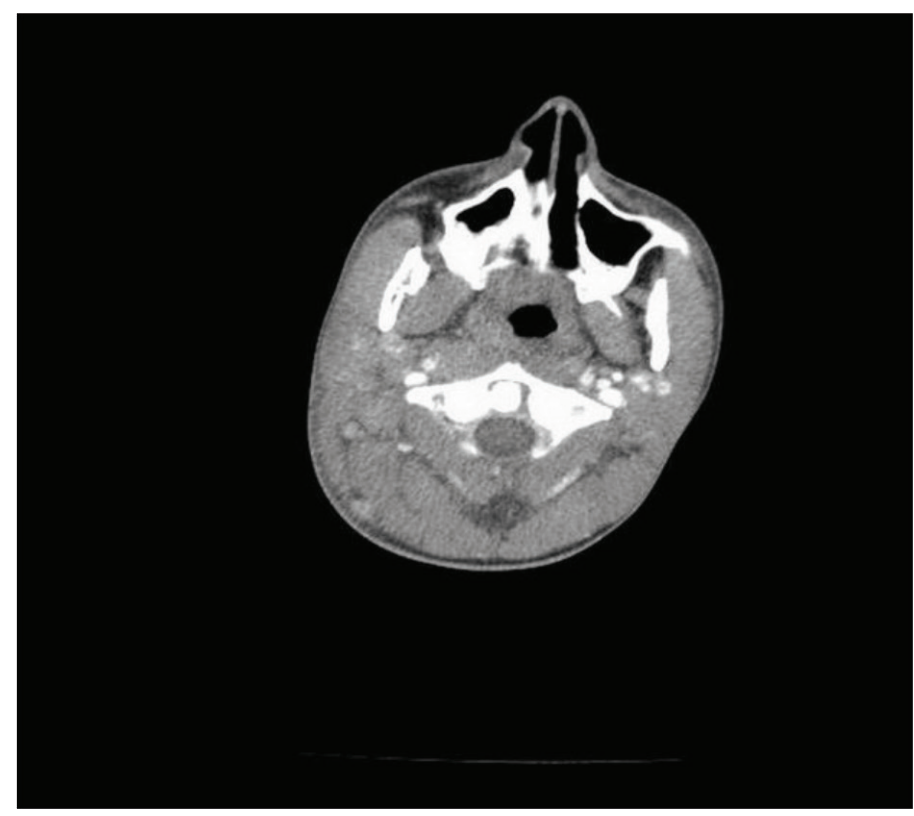

Figure 2: $\mathrm{CT}$ showing III defined subtle hypodensity in retropharyngeal space.-Like inflammatory/infective multiple enlarged cervical lymphnodes.

and found a complete cure with low molecular weight heparin, IVIG and tocilizumab. ${ }^{15}$

CLA is a common presentation in most of the viral diseases. Radiographic analysis has concluded that lymphadenopathies are characteristically absent in most SARS-COV-2 patients who were investigated using $\mathrm{CT}$, which seems rare. ${ }^{7}$ FNAC is the most preferable diagnostic tool to detect CLA. Our case was idiosyncratic as the patient was symptomatic with only fever, right sided neck pain and odynophagia and these findings were consistent with MIS-C. The testament of the patient showed viral clearance from the respiratory tract even with the probity of negative reverse transcription polymerase chain reaction 10 days prior to

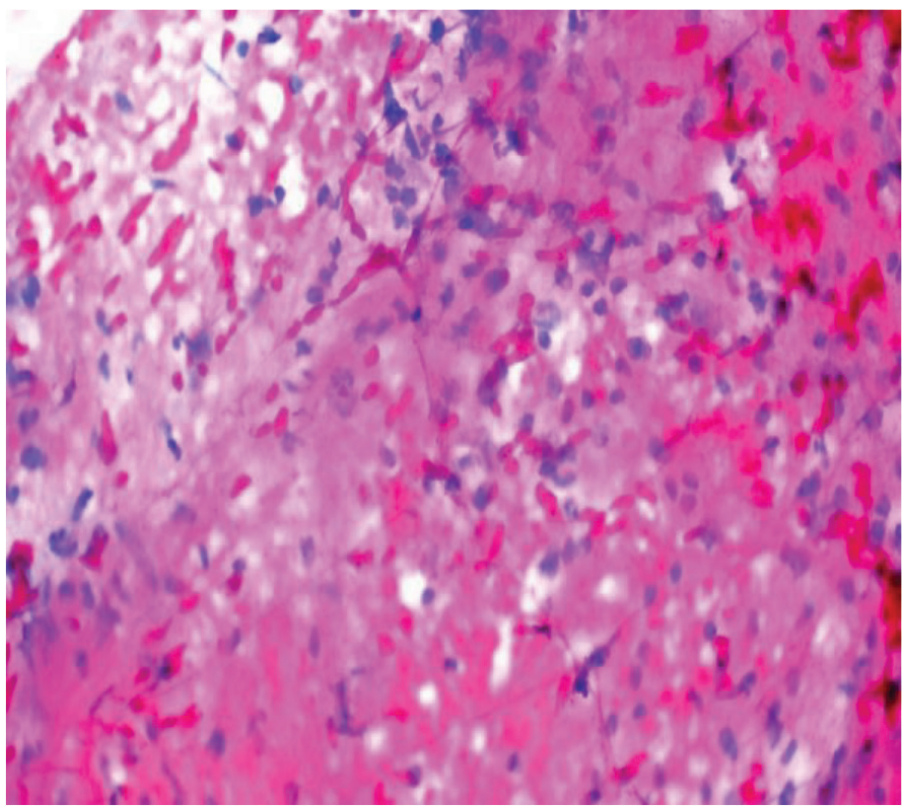

Figure 3: FNAC; smear shows blood with small mature lymphocytes and small collection of histiocytes.

Table 1: Discharge medications.

\begin{tabular}{ccc}
\hline Generic name & Dose & Frequency \\
\hline Prednisolone & $20 \mathrm{mg}-0-10 \mathrm{mg}$ & $1-0-1$ \\
Calcium acetate & $667 \mathrm{mg}$ & $0-1-0$ \\
Ascorbic acid & $500 \mathrm{mg}$ & $1-0-1$ \\
Apixaban & $2.5 \mathrm{mg}$ & $1-0-1$ \\
Esomeprazole & $20 \mathrm{mg}$ & $1-0-1$ \\
Sucralfate & $5 \mathrm{ml}$ & $1-0-1$ \\
\hline
\end{tabular}

the positive testament. So there arise no confusion between COVID-19 and MIS-C. Treatment of CLA depends on the fundamental causes as the children should be treated to give coverage of anaerobic oral vegetation. ${ }^{16}$ For the treatment of MIS-C the American college of rheumatology has advocated the use of IVIG and/or high dose of corticosteroids as first line therapy, we have been following the same criteria which have shown great clinical response. ${ }^{17}$

\section{CONCLUSION}

Early detection of the causation, initiation of treatment, follow up care and screening could decrease morbidity, mortality and expansion in the disease. Physician's care and clinical pharmacist collaboration can ultimately provide better treatment on the basis of recent healthcare guidelines which can prevent worsening of clinical status and result in rapid recovery of patient.

\section{ACKNOWLEDGEMENT}

We thank Dr. Muhammed TP, IQRAA International Hospital and Research Centre, for his guidance and support.

\section{CONFLICT OF INTEREST}

The authors declare no conflict of interest. 


\section{ABBREVIATIONS}

MIS-C: Multisystem inflammatory syndrome-children; SARS-COV-2: Severe acute respiratory system coronavirus 2; CLA: Cervical lymphadenopathy; FNAC: Fine needle aspiration cytology; CT: Computed tomography; USG: Ultrasonography; COVID-19: Coronavirus Disease 2019; KD: Kawasaki disease; IVIG: Intravenous Immunoglobulin.

\section{REFERENCES}

1. World Health Organization, WHO. Coronavirus (COVID-19) dashboard. 2021 [cited Jan 25 2021]. Available from: https://covid19.who.int/.

2. Dufort EM, Koumans EH, Chow EJ, Rosenthal EM Muse A Rowlands J Barranco MA, Maxted AM, Rosenberg ES, Easton D, Udo T, Kumar J, Pulver W, Smith L, Hutton B, Blog D, Zucker H, New York State and Centers for Disease Control and Prevention Multisystem Inflammatory Syndrome in Children Investigation Team. Multisystem inflammatory syndrome in children in New York State. N Engl J Med. 2020;383(4):347-58. doi: 10.1056/NEJMoa2021756, PMID 32598830 .

3. Castagnoli R, Votto M, Licari A, Brambilla I, Bruno R, Perlini S, Rovida F, Baldanti F, Marseglia GL. Severe acute respiratory syndrome coronavirus 2 (SARS-CoV-2) infection in children and adolescents: a systematic review. JAMA Pediatr. 2020;174(9):882-9. doi: 10.1001/jamapediatrics.2020.1467, PMID 32320004.

4. Ludvigsson JF. Systematic review of COVID-19 in children shows milder cases and a better prognosis than adults. Acta paediatr. 2020;109(6):1088-95. doi: 10.1111/apa.15270, PMID 32202343

5. Emergency. HAN archive. January 4 2021;00432 | Health Alert Network (HAN). [updated 2020 may $14 ;$;ited.

6. Riphagen S, Gomez X, Gonzalez-Martinez C, Wilkinson N, Theocharis P. Hyperinflammatory shock in children during COVID-19 pandemic. Lancet. 2020:395(10237):1607-8 doi: 10.1016/S0140-6736(20)31094-1, PMID 32386565.

7. Roldán-Santiago E, Benito-Berlinches A, Martínez-García L, Quereda C, Rodríguez-Martín E, Pérez-Elías P, López-Pintor JM, Walo-Delgado PE Moreno-Zamora A, Fernández-Velasco JI, García-Abellás P, Ballester-González R, Villar LM, Pérez-Elías MJ. SARS-CoV-2 spreads to lymph nodes and strongly expands CD4+ TEMRA cells in a patient with mild COVID-19. Clin Infect Dis. 2020:ciaa1422. doi: 10.1093/cid/ciaa1422, PMID 32948868.

8. Kabeerdoss J, Pilania RK, Karkhele R, Kumar TS, Danda D, Singh S. Severe
COVID-19, multisystem inflammatory syndrome in children, and Kawasaki disease: immunological mechanisms, clinical manifestations and management. Rheumatol Int. 2021;41(1):19-32. doi: 10.1007/s00296-020-04749-4, PMID 33219837.

9. Tam H, El Tal T, Go E, Yeung RSM. Pediatric inflammatory multisystem syndrome temporally associated with COVID-19: a spectrum of diseases with many names. CMAJ. 2020;192(38):E1093-6. doi: 10.1503/cmaj.201600, PMID 32907819.

10. Hutchison L, Plichta AM, Lerea Y, Madora M, Ushay HM. Neuropsychiatric symptoms in an adolescent boy with multisystem inflammatory syndrome in children. Psychosomatics. 2020;61(6):739-44. doi: 10.1016/j.psym.2020.06.015, PMID 32713710.

11. Waltuch T, Gill P, Zinns LE, Whitney R, Tokarski J, Tsung JW, et al. Features of COVID-19 post-infectious cytokine release syndrome in children presenting to the emergency department. Am J Emerg Med. 2020;38(10):2246:2246.e3-6. doi: 10.1016/j.ajem.2020.05.058, PMID 32471782.

12. Toubiana J, Poirault C, Corsia A, Bajolle F, Fourgeaud J, Angoulvant F Debray A Basmaci R, Salvador E, Biscardi S, Frange P, Chalumeau M, Casanova JL, Cohen JF, Allali S. Kawasaki-like multisystem inflammatory syndrome in children during the covid-19 pandemic in Paris, France: prospective observational study. BMJ. 2020;369:m2094. doi: 10.1136/bmj.m2094, PMID 32493739.

13. Riollano-Cruz M, Akkoyun E, Briceno-Brito E, Kowalsky S, Reed J, Posada R Sordillo EM, Tosi M, Trachtman R, Paniz-Mondolfi A. Multisystem inflammatory syndrome in children related to COVID-19: A New York City experience. J Med Virol. 2021;93(1):424-33. doi: 10.1002/jmv.26224, PMID 32584487.

14. Sokolovsky S, Soni P, Hoffman T, Kahn P, Scheers-Masters J. COVID-19 associated Kawasaki-like multisystem inflammatory disease in an adult. Am J Emerg Med. 2021;39:253.e1-2. doi: 10.1016/j.ajem.2020.06.053, PMID 32631771.

15. Shaigany S, Gnirke M, Guttmann A, Chong H, Meehan S, Raabe V, Louie E, Solitar B, Femia A. An adult with Kawasaki-like multisystem inflammatory syndrome associated with COVID-19. Lancet. 2020;396(10246):e8-e10. doi: 10.1016/S0140-6736(20)31526-9, PMID 32659211

16. Brook I, Frazier EH. Microbiology of cervical lymphadenitis in adults. Acta Otolaryngol. 1998;118(3):443-6. doi: 10.1080/00016489850183593, PMID 9655225.

17. Henderson LA, Canna SW, Friedman KG, Gorelik M, Lapidus SK, Bassiri H Behrens EM, Ferris A, Kernan KF, Schulert GS, Seo P, Son MBF, Tremoulet AH Yeung RSM, Mudano AS, Turner AS, Karp DR, Mehta JJ. American College of Rheumatology Clinical Guidance for Multisystem Inflammatory Syndrome in Children Associated With SARS-CoV-2 and Hyperinflammation in Pediatric COVID-19: Version 2. Arthritis Rheumatol. Version 2. 2021;73(4):e13-29. doi: 10.1002/art.41616, PMID 33277976

Article History: Received: 18-04-2021; Revised: 21-05-2021; Accepted: 15-06-2021

Cite this article: Abhijith C, BlessySamu, Sulfath TS, Ashique EP. Post Covid Multisystem Inflammatory Syndrome with Cervical Lymphadenopathy In A Young Adult. J Young Pharm. 2021;13(3):306-8. 